\title{
Collagen injections for intrinsic sphincter deficiency in the neuropathic urethra
}

\author{
JK Bennett, BG Green, JE Foote and M Gray \\ Shepherd Spinal Center Department of Urology and Emory University School of Medicine, Division of Urology, \\ 2020 Perchtree Road NW, Atlanta, Georgia, USA
}

\begin{abstract}
Twelve subjects experiencing stress urinary incontinence caused by spinal injury or myelomeningocele were treated by periurethral injection of a bulking agent, glutaraldehyde cross-linked (GAX) collagen. Of the 11 subjects who completed the program, seven were either cured or improved and four were only slightly improved or no better following injection. The valsalva (abdominal) leak point pressure (LPP) rose an average of $57 \mathrm{~cm}$ $\mathrm{H}_{2} \mathrm{O}$ (pre-treatment mean of $60 \mathrm{~cm} \mathrm{H}_{2} \mathrm{O}$ versus post-treatment mean of $117 \mathrm{~cm} \mathrm{H}_{2} \mathrm{O}$ ) and none of the patients experienced significant complications during the mean follow-up period of 24 months. Every subject injected was able to maintain an intermittent catheterization program after treatment. These data support the use of GAX collagen as an alternative or adjunct therapy to pharmacotherapy, surgical reconstruction or implantation of a prosthesis in the management of stress urinary incontinence in the neuropathic urethra.
\end{abstract}

Keywords: collagen; stress urinary incontinence; intrinsic sphincter deficiency; neuropathic urethra; neuropathic bladder.

\section{Introduction}

While considerable progress has been made in the treatment of detrusor hyperreflexia for the neuropathic bladder, the management of the intrinsic sphincter deficiency remains difficult. Pharmacotherapy, usually consisting of alpha sympathomimetic medications or imipramine, typically reduces the volume and severity of urinary leakage but rarely cures the condition. Several surgical procedures, including the implantation of an artificial urinary sphincter, are beneficial in selected patients although the risk of complications and re-operations is significant.

The injection of a urethral bulking agent offers a potential alternative for the management of stress urinary incontinence for neuropathic sphincter incompetence. Endoscopic injection of a reasonably biocompatible material may be used for the individual who fails to respond completely or tolerate the side effects of pharmacologic agents. Periurethral injection also provides an alternative for patients who are poor candidates for open surgery or implantation of a prosthetic device.

Polytetrafluoroethylene (Polytef) paste has been used for the last 20 years to treat stress urinary incontinence caused by intrinsic sphincter deficiency. ${ }^{1-3}$ While Polytef paste has proven effective in managing stress incontinence, significant complications, including periurethral abscess, urethral diverticulum and urethral wall prolapse in women have been reported. ${ }^{4}$ In addition, migration of Polytef particles have been demonstrated in animals and humans ${ }^{5,6}$ and a clinically significant inflammatory granuloma has been reported in a patient. ${ }^{7}$ Because of the potential complications of particle migration and reports of failure of the substance to produce prolonged resolution of stress incontinence, ${ }^{8}$ Polytef paste has not gained widespread clinical use.

GAX collagen is another urethral bulking agent that has undergone extensive clinical trials in the United States, Canada and Europe. The substance is a purified suspension containing approximately $95 \%$ type 1 bovine collagen and $5 \%$ type 3 bovine collagen. The cross linking process reduces the antigenicity of the collagen, thus increasing its relative biocompatibility. The cross linking process also requires a small amount of flutaraldehyde $(0.0075 \%)$ that hinders the action of collagenase, increasing GAX collagen's resistance to decomposition and reabsorption.

GAX collagen is injected under the urethral mucosa as a relatively thick, viscous suspension containing collagen and saline. Following injection, the saline is absorbed and the remaining collagen forms a soft implant that is incorporated into host tissues. The goal of therapy is to increase the coaptation of the urethral walls enhancing urethral sphincter competence and preventing stress urinary incontinence..$^{9,10}$

Initial experiences with GAX collagen implants have shown positive results for several groups of patients. In 1989, Shortliffe et al ${ }^{11}$ treated 17 adults with urethral 
sphincter deficiency with GAX collagen. In nine of 17 $(53 \%)$ patients, the injections either cured or significantly improved stress urinary incontinence. In a multicenter study, McGuire et $a l^{9}$ demonstrated significant improvement or cure in 52 of 60 subjects $(80 \%)$ managed by periurethral collagen injections. Eckford and Abrams ${ }^{12}$ injected GAX collagen into 20 women with stress urinary incontinence; $15(80 \%)$ were symptomatically improved and cured. Wan et al ${ }^{13}$ injected collagen in eight children experiencing stress incontinence caused by congenital birth defects, including spina bifida. Seven subjects $(88 \%)$ were either cured or improved and one child remained unchanged. In addition, Herschorn et al $^{14}$ injected GAX collagen into 41 patients, including four patients with neuropathic intrinsic sphincter deficiency. Among the women, 28 of $31(90 \%)$ were improved or cured while 7 of 10 males injected $(70 \%)$ were cured or improved. All of the patients with neuropathic sphincter deficiency experienced at least some improvement in their incontinence following treatment. We are reporting our experience with periurethral GAX collagen injections in 12 subjects with stress urinary incontinence caused by neuropathic urethral dysfunction.

\section{Materials and methods}

Twelve patients with stress urinary incontinence caused by neuropathic sphincter deficiency underwent injection of GAX collagen. One patient withdrew prior to completion of the course of treatment due to fear of hypersensitivity to the collagen preparation even though no objective evidence of an allergic response was noted. The study was approved by the institutional review committee of the Shepherd Spinal Center and each subject gave permission prior to enrollment in the investigation. The research was a part of a multicenter clinical study of GAX collagen injections in the treatment of stress urinary incontinence caused by intrinsic sphincter deficiency.

Within the study group, five of 11 subjects were myelodysplastic, five of 11 were spinal cord injured and one patient was rendered paraplegic from a spinal cord tumor. The patient demographics and the etiologies of the neuropathic urethra are listed in Tables 1 and 2. All

Table 1 Patient characteristics

\begin{tabular}{llll}
\hline Subject & Sex/Age & & Etiology \\
\hline 1 & M/30 & SCI & $\left\{\mathrm{T}_{12}\right\}$ \\
2 & $\mathrm{M} / 38$ & SCI & $\left\{\mathrm{T}_{12}\right\}$ \\
3 & $\mathrm{M} / 31$ & SCI & $\left\{\mathrm{T}_{12}\right\}$ \\
4 & $\mathrm{M} / 20$ & Tumor & $\left\{\mathrm{L}_{2}\right\}$ \\
5 & $\mathrm{M} / 39$ & SCI & $\left\{\mathrm{L}_{1}\right\}$ \\
6 & $\mathrm{M} / 06$ & SCI & $\left\{\mathrm{T}_{3}\right\}$ \\
7 & $\mathrm{~F} / 38$ & MMC & \\
8 & $\mathrm{M} / 32$ & MMC & \\
9 & $\mathrm{M} / 25$ & MMC & \\
10 & M/23 & MMC & \\
11 & F/50 & MMC & \\
\hline
\end{tabular}

Table 2 Results

\begin{tabular}{llc}
\hline No. & $\begin{array}{c}\text { Pre-treatment } \\
\text { LPP/Grade }\end{array}$ & $\begin{array}{c}\text { Post-treatment } \\
\text { LPP/Grade }\end{array}$ \\
\hline $\begin{array}{l}\text { Cured } \\
3\end{array}$ & $39 \mathrm{~cm} \mathrm{H}_{2} \mathrm{O} / 2.7$ & $171 \mathrm{~cm} \mathrm{H}_{2} \mathrm{O} / 0$ \\
Improved & $84 \mathrm{~cm} \mathrm{H}_{2} \mathrm{O} / 2.5$ & $140 \mathrm{~cm} \mathrm{H}_{2} \mathrm{O} / 1.3$ \\
$\begin{array}{l}\text { No change } \\
4\end{array}$ & $51 \mathrm{~cm} \mathrm{H}_{2} \mathrm{O} / 2.5$ & $50 \mathrm{~cm} \mathrm{H}_{2} \mathrm{O} / 2.5$ \\
\hline
\end{tabular}

patients were managed by an intermittent catheterization program prior to injection. A condom catheter was used to contain urinary leakage among the males and pads or a diaper device were used for containment among the females.

The diagnosis of stress urinary incontinence was based on evaluation that included a history and physical examination, and videourodynamics using a technique previously described. ${ }^{15}$ Urethral sphincter incompetence was diagnosed when the anatomical configuration of the bladder outlet showed funneling of the proximal urethra during filling cystometry in the upright position in the absence of a detrusor contraction. Most of these patients were areflexic. The average capacity was $432 \mathrm{cc}$ (range 220-600) and the average compliance $46 \mathrm{cc} / \mathrm{cm} \mathrm{H}_{2} \mathrm{O}$ (range 10-125). The diagnosis was confirmed by measurement of a valsalva (abdominal) LPP. The LPP is measured as $\mathrm{cm}_{2} \mathrm{O}$; it is identified by increasing abdominal pressure until leakage is observed. When feasible, the patient is asked to gradually contract the abdominal muscles or cough to raise intravesical pressure. If the patient cannot voluntarily contract those muscles, the intravesical pressure is raised by gradually compressing the suprapubic area until leakage occurs.

The severity of urinary leakage was evaluated using a questionnaire to determine the circumstances during which the patient experienced incontinence. A scale of $0-3$ was used where grade 0 indicates no leakage, grade 1 indicates leakage with brisk exercise or lifting relatively heavy objects, grade 2 indicates leakage with minimal exertion, and grade 3 signifies incontinence in the absence of apparent physical exertion including sleep. The quantification of the amount of urine lost was not used because of the inconsistency of bladder programs and means to control incontinence by these patients.

Inclusion criteria were limited to individuals with neurogenic bladder dysfunction and stress urinary incontinence caused by intrinsic sphincter deficiency. Exclusion criteria included extraurethral leakage and a known intolerance of GAX collagen. Subjects who met the criteria for inclusion underwent a skin test to exclude the possibility of hypersensitivity to GAX collagen prior to any suburethral injections. Prior to treatment, a urine culture was obtained and bacteriuria was eradicated.

Cystoscopy was then performed via a 21 French panendoscope and 12 degree lens. After cystoscopic 
inspection, the bladder was emptied. For women, a 21 gauge spinal needle was inserted periurethrally at the 3 o'clock position and advanced obliquely into the submucosal space. Depth to the bladder and proximal urethra was confirmed by wiggling the needle and observing the movement cystoscopically. A quantity of GAX collagen that was sufficient to cause coaptation of the urethra without causing mucosal rupture was then injected. The needle was then replaced at the 9 o'clock position and a similar procedure was performed. Care was taken to prevent bladder overdistension since reinsertion of the cystoscopic sheath into the bladder can cause collagen displacement and mucosal disruption. Patients are instructed not to catheterize for at least $30 \mathrm{~min}$ following the procedure.

For men with sensory preservation, a pudendal nerve block was performed by injecting $10-20 \mathrm{cc}$ of $2 \%$ Xylocaine at the ischial tuberosities. In addition, 2\% Xylocaine jelly was inserted into the urethra. Cystoscopy was then performed as described above. A 21 gauge needle attached to a 7 French catheter was inserted through the cystoscope. The needle was advanced into the bladder neck mucosal space and GAX collagen was injected as described above at the 3 and 9 o'clock positions. Once total coaptation of the bladder neck had been accomplished, additional injections were performed along the prostatic and membranous urethra to create a more complete coaptation of the entire proximal urethra. Again, particular care was taken to avoid overdistension of the bladder.

Following urethral injection, the patients were evaluated at 1,6 , and 12 months. These evaluations consisted of valsalva LPP and grading of incontinence severity. Recurrence or persistence of stress urinary leakage was managed by repeat injection until the greatest possible continence was achieved.

\section{Results}

Three of the 11 subjects who completed treatment were cured and four were significantly improved following treatment. In contrast, four patients failed to experience significant improvement, even after multiple injections (Table 3). Prior to injection, the mean valsalva LPP was $60 \mathrm{~cm} \mathrm{H}_{2} \mathrm{O}$ compared to $117 \mathrm{~cm}$ $\mathrm{H}_{2} \mathrm{O}$ following treatment. Among the patients who were cured, the valsalva LPP rose an average of $135 \mathrm{~cm}$ $\mathrm{H}_{2} \mathrm{O}$ following injection. The patients who improved their urinary incontinence by at least one grade experienced an average increase in valsalva LPP of $57 \mathrm{~cm} \mathrm{H}_{2} \mathrm{O}$ from a mean of $84 \mathrm{~cm} \mathrm{H}_{2} \mathrm{O}$ to $140 \mathrm{~cm} \mathrm{H}_{2} \mathrm{O}$. In contrast, the four subjects who failed to improve their incontinence by one grade also failed to improve the valsalva LPP. Among these four subjects, the LPP declined slightly from an average of $51 \mathrm{~cm} \mathrm{H}_{2} \mathrm{O}$ before injection to $50 \mathrm{~cm} \mathrm{H}_{2} \mathrm{O}$ following multiple treatments.

Typically, female subjects treated required fewer injections although the volume of collagen used for males and females was similar. The women treated required an average of 2.5 injections (range 2-3) while the men treated required an average of 3.6 injections (range 3-8). The average volume of GAX collagen injected into the females was $54 \mathrm{cc}$ compared to an average of $55 \mathrm{cc}$ among the males. The subjects who were improved or cured following treatment required an average of two injections while those who failed to improve were injected an average of 4.8 times. The mean volume of collagen required for patients who were improved or cured was $39 \mathrm{cc}$ compared to $71 \mathrm{cc}$ for those who failed to improve.

No significant complications were experienced during the follow-up period that averaged 24 months from the time of first injection (range 12-32 months). All of the patients experienced urinary tract infections following injections but all had experienced these infections prior to treatment. A single patient experienced brief difficulty with self intermittent catheterization following collagen injection.

\section{Discussion}

GAX collagen is an effective treatment modality for stress urinary incontinence caused by intrinsic sphincter deficiency in the neuropathic urethra. The mechanism by which collagen injections improve continence is different from the strategy employed during open surgery, implantation of a prosthetic device or pharmacotherapy.

In the neuropathic urethra, sphincter deficiency is caused by a failure of tone related to denervation of muscle fibers in the bladder neck, proximal urethra, rhabdosphincter and periurethral muscles. Open surgical procedures improve sphincter competence by correcting the anatomic defect of pelvic descent or by compressing the proximal third of the urethra. Implantation of an artificial urinary sphincter device improves urethral competence by extrinsic compression of the urethral lumen while pharmacotherapy enhances tone by stimulating the alpha excitatory nerves producing muscle fiber contraction. In contrast, injection of a periurethral bulking agent, such as GAX collagen, enhances the apposition of the urethral walls, increasing the efficiency of compression in the sphincter mechanism. Thus, the valsalva LPP will rise in response to treatment and continence will improve, while the maximum urethral closure pressure will remain relatively unaffected. We recognize that the LPP is dependent upon catheter size as well as the rate of infusion during the cystometrogram. Because of these variables, a small caliber urethral catheter (5 French) and a slow infusion rate will enhance reproductibility. ${ }^{16}$

The reasons for failure among four subjects in this investigation remain unclear. It is possible that the urethral mucosa within these individuals was incapable of effective apposition in response to collagen injection because of scarring or fibrosis of the urethral mucosa. It is possible that scarring may adversely affect the urethra's ability to retain the collagen long enough for integration with local tissues. It may be argued that the muscular elements of the sphincter mechanism were weaker among the individuals who failed to improve following injection with collagen, but this observation is 
contradicted by comparison of pre-treatment and posttreatment valsalva LPPs (Table 2). Future investigation should focus on the prediction of patients who are most likely to benefit from collagen injection and identification of specific risk factors that predispose a person to treatment failure.

\section{Conclusion}

In conclusion, GAX collagen is safe and effective for the treatment of sphincter incompetence in the neuropathic urethra. There were no complications and $81 \%$ of the patients treated were either cured or improved. There were better clinical results among patients with lower leak point pressures. We believe that future studies should be directed toward delineating which clinical and urodynamic features would predict success.

\section{References}

1 Politano VA, Small MP, Harper JM, Lynne MC. Periurethral teflon injection for urinary incontinence. J Urol 111: 180.

2 Politano VA. Periurethral teflon injection for urinary incontinence. Urol Clin North Am 5: 415.

3 Lotenfoe R, O'Kelly JK, Helal M, Lockhart JL. Periurethral polytetrafluoroethylene past injection in incontinent female subjects: Surgical indications and improved surgical technique. J Urol 149: 279-282.
4 Kiilholma PJ et al. Complications of Teflon injections for stress urinary incontinence. Neurourol Urodynam 12: 131-138

5 Malizia AM et al. Migration and granulomatous reaction after periurethral injection of Polytef (Teflon). JAMA 251: 3277.

6 Mittleman RE, Maricini JV. Pulmonary Teflon granulomas following periurethral Teflon injection for urinary incontinence. Arch Pathol Lab Med 107: 611.

7 Claes $\mathrm{H}$ et al. Pulmonary migration following periurethral polytetrafluoroethylene injection for urinary incontinence. J Urol 142: 821-822.

8 von Fischer $\mathrm{W}$ et al. Is Teflon injection still justified for treatment of female urinary incontinence. Zentrabl Gynaekol 108: 833 .

9 McGuire EJ et al. Treatment of urethral incontinence by collagen injection - one year follow up. $J$ Urol 141: 538.

10 McGuire EJ, Appel RA. Collagen injection for the dysfunctional urethra. Contemp Urol 1991: 11-19.

11 Shortliffe LMD et al. Treatment of urinary incontinence by the periurethral implantation of glutaraldehyde cross-linked collagen. $J$ Urol 141: 538.

12 Eckford SD, Abrams P. Para-urethral collagen implant for female stress incontinence. Br J Urol 68: 586-589.

13 Wan J, McGuire EJ, Bloom DA, Ritchey ML. The treatment of urinary incontinence in children using glutaraldehyde crosslinked collagen. J Urol 148 : 127-130.

14 Herschorn S, Radomski SB, Steele D. Early experience with intraurethral collagen injections for urinary incontinence. J Urol 148: $1797-1800$.

15 Killorin W, Gray M, Bennett JK, Green BG. The value of urodynamics and bladder management in predicting upper tract complications in male spinal cord injury patients. Paraplegia 30: 437-441.

16 Decter RM, Harpster L. Pitfalls in the determination of leak point pressure. J Urol 148: 588-591. 